\title{
Ascorbate (vitamin C) induces cell death through the apoptosis-inducing factor in human breast cancer cells
}

\author{
SEUNG-WOO HONG ${ }^{1,2^{*}}$, DONG-HOON JIN ${ }^{1 *}$, EUN-SIL HAHM ${ }^{3}$, SEI-HYUN YIM ${ }^{1}$, \\ JONG-SEOK LIM ${ }^{1}$, KEUN-IL KIM ${ }^{1}$, YOUNG YANG ${ }^{1}$, SOO-SUK LEE ${ }^{4}$, JAE-SEUNG KANG ${ }^{3}$, \\ WANG-JAE LEE ${ }^{3}$, WON-KEUN LEE ${ }^{2}$ and MYEONG-SOK LEE ${ }^{1}$
}

\begin{abstract}
${ }^{1}$ Research Center for Women's Diseases, Division of Biological Sciences, Sookmyung Women's University, Seoul 140-742; ${ }^{2}$ Department of Biological Sciences, Myongji University, San 38-2 Namdong, Cheoin-gu, Youngin, Gyeonggido 449-728; ${ }^{3}$ Department of Anatomy and Tumor Immunity Medical Research Center, Seoul National University College of Medicine, Seoul 110-744; ${ }^{4}$ Samsung Advanced Institute of Technology, Suwon 440-600, Korea
\end{abstract}

Received March 8, 2007; Accepted May 16, 2007

\begin{abstract}
Although ascorbate (Vitamin C) has been shown to inhibit cell growth and induce cell death in variety of cancer cells, results reported in other studies are inconsistent with this conclusion. It was previously reported that ascorbate induces apoptosis in human breast cancer cells. However, the molecular mechanism for this is not clear. In this study, we demonstrate that ascorbate induces cell death through the apoptosis-inducing factor (AIF) in the human breast cancer cell lines, SK-BR3 and Hs578T, but not in a normal breast cell line, Hs578. Ascorbate treatment caused the nuclear translocation of AIF, which is retained in the mitochondria in healthy cells, but caspase cleavage is not induced. Moreover, MG132, an inhibitor of AIF release from mitochondria, blocked the induction of cell death. Furthermore, cells that had been treated with human AIF-specific siRNA resisted cell death induced by ascorbate, implying that the translocation of AIF from mitochondria to the nucleus is responsible for ascorbate-mediated cell death. Therefore, these results suggest that ascorbate activates a caspase-independent and AIFmediated cell death pathway in human breast cancer cells, SK-BR3, and Hs578T.
\end{abstract}

\section{Introduction}

The effect of ascorbate (vitamin C) in cancer treatment remains controversial (1). It was previously reported that ascorbate induces cell cycle arrest and apoptosis in various tumor cells, such as lymphoma cells and leukemia cells (2-4), melanoma

Correspondence to: Dr Myeong-Sok Lee, Division of Biological Sciences, Sookmyung Women's University, Seoul 140-742, Korea E-mail: mslee@sookmyung.ac.kr

${ }^{*}$ Contributed equally

Key words: ascorbate (vitamin C), apoptosis-inducing factor, caspase, cell death, $\mathrm{Ca}^{2+}$ cells (5), brain tumor cells $(6,7)$, prostate cancer cells $(8,9)$, and stomach cancer cells (10). However, the molecular mechanism of ascorbate as an anti-tumor effector has not been fully elucidated.

Apoptosis is a tightly programmed form of cell death in which cells actively participate in their own destruction. Apoptosis is mainly triggered by either the extrinsic pathway (11), which is also known as the death receptor pathway, or by the intrinsic pathway (12), which may affect cellular organelles, including the nucleus, the endoplasmic reticulum (ER), lysosomes or mitochondria (13). Both the extrinsic and the intrinsic pathways of apoptosis lead to cell shrinkage, chromatin condensation, nuclear fragmentation, blebbing and phosphatidylserine exposure on the surface of the plasma membrane (14).

Apoptotic cell death largely proceeds in either a caspasedependent or caspase-independent manner (15). Iit has been discovered that, in response to apoptotic stimuli, mitochondria can also release caspase-independent cell death effectors such as the apoptosis-inducing factor (AIF) (15-17). AIF, when released from mitochondria, is translocated to the nucleus where it triggers chromatin condensation and large DNA fragmentation in a caspase-independent manner, indicating that it is an important factor in cell death in MCF-7 cells with depleted caspase 3 or 8 (18).

In this study, we examined the anti-cancer effect of ascorbate using human breast cancer cells. We showed that ascorbate treatment induced apoptosis through the nuclear translocation of AIF. We also found that ascorbate-induced apoptosis was not continuous with $\mathrm{Ca}^{2+}$ signaling and caspasedependent apoptosis, using pharmaceutical inhibitors, such as nifedipine, a $\mathrm{Ca}^{2+}$ inhibitor, and a pan-caspase inhibitor. We report that human breast tumor-derived cell lines are sensitive to ascorbate-induced cell death and discuss the potential mechanism involved in this process.

\section{Materials and methods}

Cell cultures, materials and siRNA transfection. Hs578T and SK-BR3, human breast carcinoma cells, and Hs578, human 
breast normal cells were maintained in DMEM supplemented with 10\% FBS (Life Technologies, Inc., Grand Island, NY) and penicillin-streptomycin $(50 \mathrm{U} / \mathrm{ml})$. Nifedipine as $\mathrm{Ca}^{2+}$ blocker, pan-caspase inhibitor, and MG132 as blocker of AIF release (19) were purchased from Sigma Chemical Company. Cells transfected with the siRNA of human AIF (5'GAUCCU CCCCGAAUACCUCTT-3') were transiently transfected using Lipofectamine 2000 (Invitrogen, Carlsbad, CA). Scrambled RNA as control was obtained from Proligo LLC (Boulder, CO, USA).

Cell cytotoxicity. Cell viability was determined by trypan blue exclusion, by counting at least 500 cells in each culture. Cells were treated with $0.1,0.2,0.5$, and $1 \mathrm{mM}$ of ascorbate (Sigma, St. Louis, MO) for $24 \mathrm{~h}$, and then live and dead cells were counted using the trypan blue exclusion assay.

Immunoblot analysis. Cells lysates were prepared with RIPA lysis buffer (50 mM Tris-HCl, pH 7.5, $50 \mathrm{mM} \mathrm{NaCl}, 1 \mu \mathrm{M}$ EGTA, $1 \%$ Triton X-100, $50 \mathrm{mM} \mathrm{NaF}, 5 \mathrm{mM} \mathrm{Na}_{3} \mathrm{VO}_{4}, 10 \mathrm{mM}$ $\mathrm{Na}_{4} \mathrm{P}_{2} \mathrm{O}_{7}, 0.1 \mathrm{mM}$ phenylmethylsulfonyl fluoride, $1 \mu \mathrm{g} / \mathrm{ml}$ aprotinin, $1 \mu \mathrm{g} / \mathrm{ml}$ pepstatin A, $1 \mu \mathrm{g} / \mathrm{ml}$ leupeptin, and $1 \mathrm{mM}$ DTT). Protein extracts were normalized for concentration using the Bradford assay and $20 \mu \mathrm{g}$ of total cell protein per sample was subjected to sodium dodecylsulfate-polyacrylamide gel electrophoresis (SDS-PAGE) and then transferred to a PolyScreen membrane (NEN, Boston, MA). The membranes were blocked with $5 \%$ nonfat dry milk in TBST buffer $(20 \mathrm{mM}$ Tris- $\mathrm{HCl}, \mathrm{pH} 7.4,150 \mathrm{mM} \mathrm{NaCl}, 0.1 \%$ Tween-20) and probed with one of the following antibodies: anti-cleaved caspase 9, anti-cleaved capase-3, antibodies (Cell Signaling Technology, Beverly, MA); anti-tubulin, AIF, and Hsp60 antibodies (Santa Cruz Biotechnology, Santa Cruz, CA). The primary antibodies were detected with either goat anti-mouse, goat anti-rabbit, or donkey anti-goat horseradish peroxidase-conjugated secondary antibody by enhanced chemiluminescence (Amersham, Buckinghamshire, UK).

Preparation of mitochondrial extracts. Cells were resuspended in an isotonic buffer containing $10 \mathrm{mM}$ HEPES pH 8.0, $250 \mathrm{mM}$ sucrose, $1 \mathrm{mM}$ EDTA, $1 \mathrm{mM}$ EGTA, $1 \mathrm{mM}$ DTT, $0.1 \mathrm{mM}$ phenylmethylsulfonyl fluoride (PMSF), $1 \mu \mathrm{g} / \mathrm{ml}$ leupeptin, $1 \mu \mathrm{g} / \mathrm{ml}$ pepstatin $\mathrm{A}$, and homogenized using a 26-gauge syringe needle. Cell homogenates were spun at $1,000 \mathrm{~g}$ to remove unbroken cells, nuclei, and heavy membranes. The supernatant was then spun again at 14,000 g for $30 \mathrm{~min}$ to yield the mitochondrial (pellet) and cytosolic (supernatant) fractions. The mitochondrial fraction was washed once with extraction buffer, and finally resuspended in RIPA buffer for Western blot analysis.

Immunofluorescence analyses. For AIF staining, cells were fixed with $\mathrm{PBS} / 3.7 \%$ paraformaldehyde at RT for $15 \mathrm{~min}$, and then permeabilized in PBS/0.1\% Triton X-100/0.1 mg/ml RNase $\mathrm{A}$ at $37^{\circ} \mathrm{C}$ for $30 \mathrm{~min}$. The permeabilized cells were treated with $0.5 \mathrm{mg} / \mathrm{ml}$ of $\mathrm{NaBH}_{4}$ so that autofluorescence was reduced. The cells were then immunostained by the antiAIF goat polyclonal antibody (Santa Cruz Biotechnology) at 1:100 dilution, and then by Mitotracker Orange CMTMRos (Molecular Probes, Eugene, OR), and DAPI. After washing

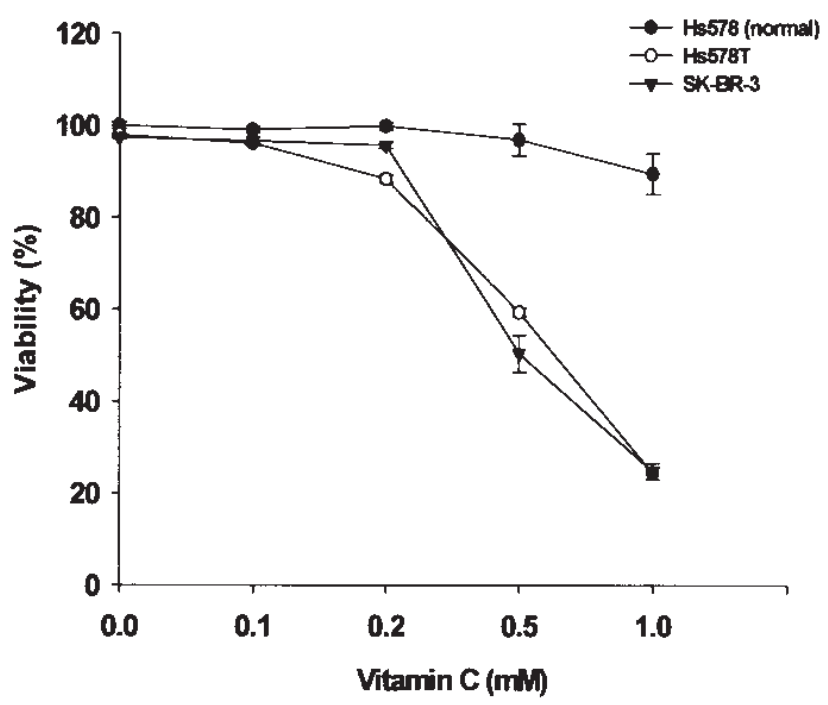

Figure 1. Ascorbate induces cell death in human breast cancer cells. Human breast cancer cells, Hs578T and SKBR3 were treated with $0.1,0.2,0.5$, and $1 \mathrm{mM}$ of ascorbate for $24 \mathrm{~h}$, and the cell numbers were counted at $24 \mathrm{~h}$, and cell death was determined by counting the number of trypan blue stained cells after $24 \mathrm{~h}$. Human normal breast cells, Hs578 were also treated with the indicated doses of ascorbate, and cell numbers were monitored at the times indicated. Each point represents the average result of three independent experiments.

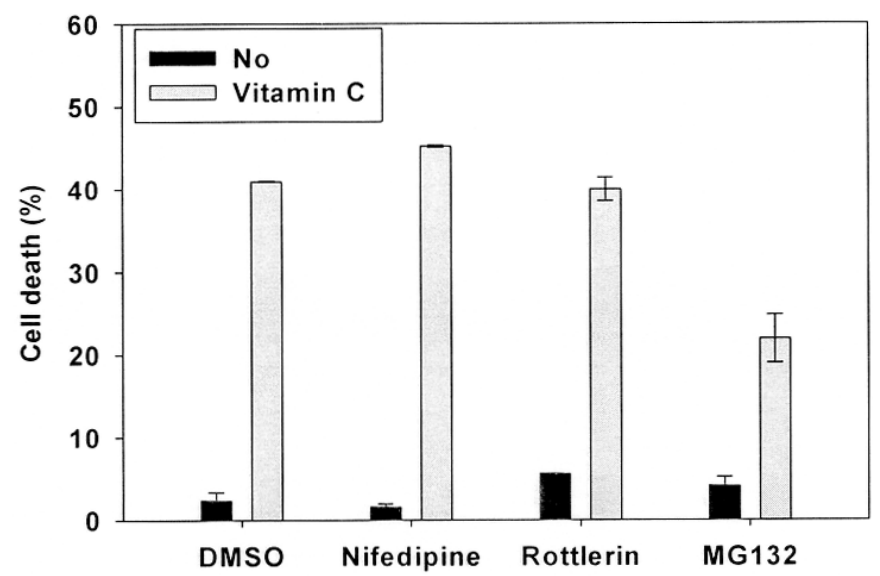

Figure 2. Ascorbate does not induce cell death through $\mathrm{Ca}^{2+}$ signal and caspase-dependent pathway. The effect of inhibitors on ascorbate-induced cell death. Cells were treated with either $10 \mu \mathrm{M}$ nifedipine, $3 \mu \mathrm{M}$ MG132, or $10 \mu \mathrm{M}$ PKC- $\delta$ inhibitor before ascorbate treatment $(0.5 \mathrm{mM})$, and cell death was determined by counting the number of trypan blue-stained cells after $24 \mathrm{~h}$. The percentages of trypan blue-positive cells representing cell death are shown.

3 times with PBS, coverslips were mounted on microscope slides using ProLong antifade mounting reagent (Molecular Probes). The slides were analyzed by an Olympus DP50 digital camera (Olympus Optical, Japan).

\section{Results}

Ascorbate can induce cell death in human breast cancer cells. We examined cell viability in human breast cancer cells, Hs578T, SKBR3 and normal cells, Hs578 during treatment with various doses of ascorbate. Cancer cells treated with ascorbate induced cell death after $24 \mathrm{~h}$, whereas normal cells 


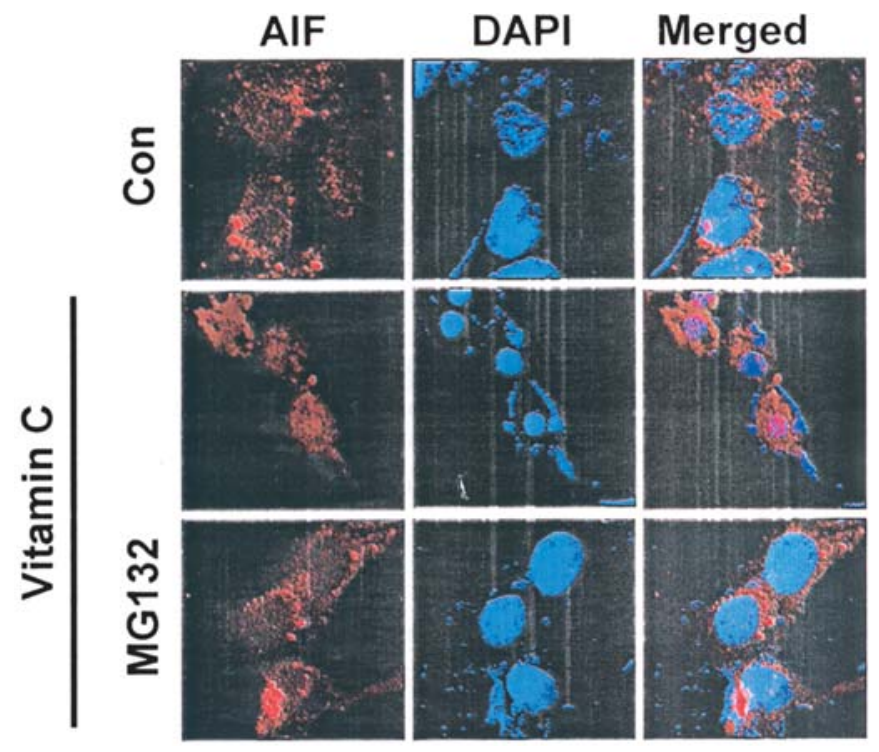

Figure 3. Ascorbate induces cell death through the nuclear translocation of AIF. Immunostaining of AIF in ascorbate-treated cells. Cells were immunostained for AIF as described in Materials and methods. Cells were then fixed and stained with DAPI (blue) or an antibody specific for the AIF (red)

were not affected (Fig. 1). The cell death-inducible dose of ascorbate in Hs578T and SKBR3 was lower in other cancer cells, implying that sensitivity to cell death by ascorbate in both cells is higher. In addition, normal breast cells, Hs578, were derived from a patient who also produced Hs578T, breast cancer cells. In normal cells and cancer cells derived from the patient, ascorbate induced cell death was observed only in breast cancer cells, Hs578T, but no cytotoxicity was found in the case of normal breast cells, Hs578, suggesting that ascorbate could be used as an anti-tumor agent without any significant side-effects.

Ascorbate induces caspase-independent cell death through the nuclear translocation of the apoptosis inducing factor. To investigate how ascorbate induces cell death, we examined key regulators in ascorbate-induced cell death after various treatments withinhibitors, such as nifedipine, a $\mathrm{Ca}^{2+}$ blocker, a pan-caspase inhibitor, and MG132 as a blocker of AIF release (19), and observed whether cell death induced by ascorbate was suppressed by these various inhibitors. It was previously reported that ascorbate induces apoptosis via $\mathrm{Ca}^{2+}$ signals of the endoplasmic reticulum (ER), which regulates protein synthesis, protein folding and trafficking, intracellular $\mathrm{Ca}^{2+}$ levels (20), and participates in the initiation of cell death signaling (21). We found that the blockage of the $\mathrm{Ca}^{2+}$ signal by nifedipine did not suppress ascorbate-induced cell death, and apoptosis was also not inhibited by pan-caspase inhibitor in human breast cancer cells, Hs578T and SKBR3 (Fig. 2). However, ascorbate-induced cell death was suppressed after MG132 treatment, which blocks AIF release (19) (Fig. 2). We therefore examined the activities of caspase 3 and 9 , but neither were activated upon ascorbate treatment (data not shown). Therefore, these results imply that ascorbate induces cell death through the nuclear translocation of AIF without activation of either of the caspases.
A

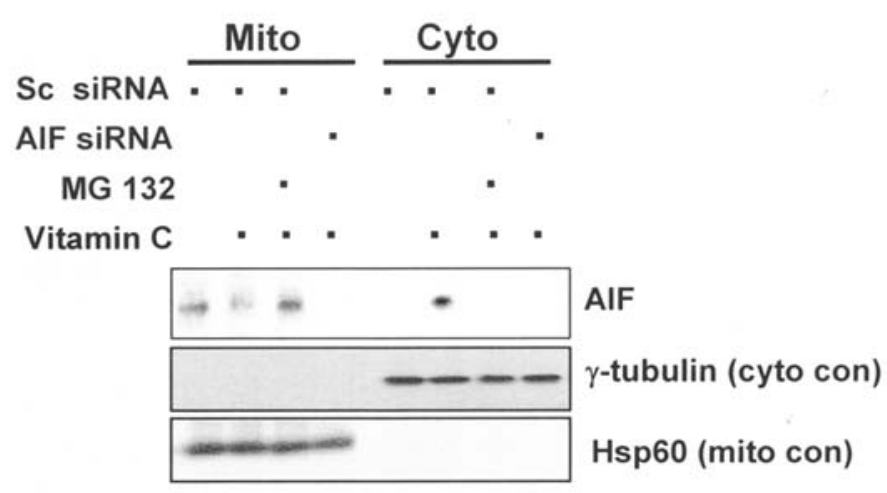

$\mathbf{B}$

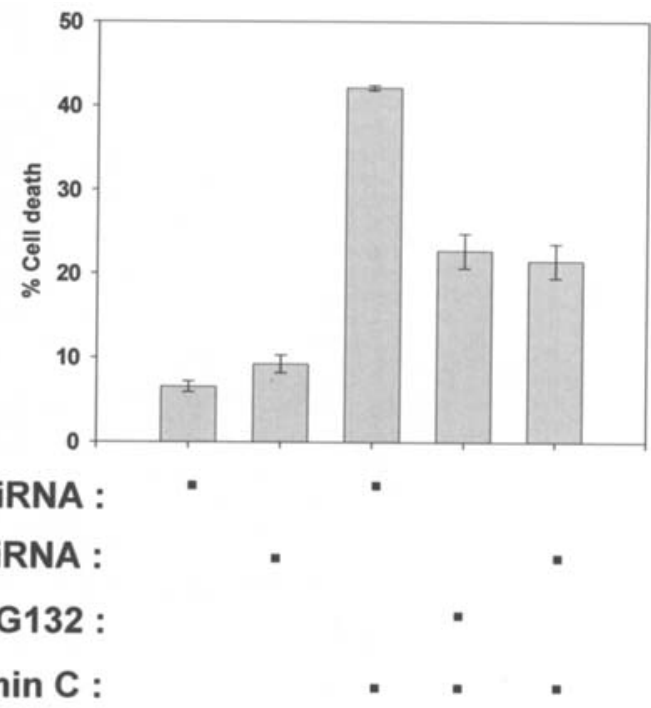

Figure 4. The effect AIF siRNA on ascorbate-induced cell death. Cells were transfected with the indicated concentrations of human AIF SiRNA or scrambled RNA for $24 \mathrm{~h}$, and then treated with ascorbate for an additional 24 h. (A) Mitochondria fractions were prepared to detect cytosol and mitochondrial AIF. Mitochondria and cytosol extracts were prepared as described in Materials and methods. Hsp60, which is localized in mitochondria, was used as a loading control for these mitochondria fractions. (B) Dead cell percentage was measured by the trypan blue staining as in Figures 1 and 2.

To confirm the translocation of AIF from mitochondria to the nucleus upon ascorbate treatment, we carried out immunostaining for AIF (Fig. 3). Co-staining with Mitotracker Orange CMTMRos to label AIF (red) revealed that the punctate nucleic DAPI staining (blue) colocalizes with AIF, yielding a baby blue composite signal when DAPI and Mitotracker images of AIF were overlaid. The immunostaining experiments showed that AIF proteins were mainly localized in the mitochondria. Further immunostaining showed that AIF became localized in nuclei only after ascorbate treatment (Fig. 3).

We next examined the effects of AIF silencing using small interfering RNA (siRNA). Cell fractionation showed that AIF protein was weakly detected in the mitochondrial fraction, but strongly in the cytosol in ascorbate-treated cells, while cytosolic AIF protein levels after ascorbate treatment were decreased in AIF-siRNA-treated cells as compared with that of cells treated with scrambled RNA, equivalent to the cells that had been treated with MG132 (Fig. 4A). In parallel with AIF silencing, the populations of dead cells were decreased in the presence of ascorbate (Fig. 4B), implying that AIF silencing renders cells resistant to ascorbate. These results 
suggest that the nuclear translocation AIF is essential for ascorbate-induced cell death in human breast cancer cells and that ascorbate could be a potential anti-tumor agent.

\section{Discussion}

The findings herein show that ascorbate induces cell death through the release of AIF from mitochondria in human breast cancer cells in a caspase-independent manner. However, normal breast cells, Hs578, which were derived from the same patient who was the source of Hs578T, breast cancer cells, were insensitive to vitamin $\mathrm{C}$.

The use of ascorbate for breast cancer therapy should be viewed with some caution because of an overall lack of clear research findings. Recent studies reported that a mixture of ascorbate and other compounds also induces cell cycle arrest or cell death only in human breast cancer cells. For example, breast cancer cell proliferation was inhibited by extracts from cultured strawberries (22), a cocktail of ascorbate and copper (23), a mixture of retinoic acid and ascorbate (24), and a mixture of lysine, proline, ascorbate and green tea extract was reported to have antitumor activity (25), whereas other groups reported that ascorbate inhibits tumor angiogenesis through the suppression of HIF- $1 \alpha$ and HIF transcriptional targets (26).

Ascorbate induced cell death in human breast cancer cells, Hs578T and SK-BR-3, while failed to induce cell death in human normal breast cells, Hs578. Therefore, we analyzed molecular mechanisms by which ascorbate induces cell death (Fig. 1). It has previously been reported that ascorbate induces cell death via PKC $\delta$ pathway in neuroblastoma cells (27), the $\mathrm{Ca}^{2+}$ signal in human hepatoma cells (28), glioblastoma cells, renal carcinoma cells (29), and the caspase-dependent pathway in melanoma cells (30). Based on these studies, we examined the effect of some chemical inhibitors, such as rottlerin, a PKC $\delta$ specific inhibitor, nifedipine, a $\mathrm{Ca}^{2+}$ signal blocker, a pancaspase inhibitor, and MG132, an AIF blocker (19), on ascorbate-induced cell death. Rottlerin, nifedipine, and pancaspase inhibitor (data not shown) had no effect on ascorbateinduced cell death. However, MG132 suppressed the cell death induced by ascorbate (Fig. 2). These results suggest that ascorbate induces cell death through a caspase-independent pathway in human breast cancer cells. The release of AIF from mitochondria by ascorbate treatment was clearly found by immunostaining using AIF-specific antibody, and the inhibitory effect of MG132 on AIF release was also confirmed (Fig. 3).

We next examined the effects of AIF silencing using interfering RNA (siRNA) (31). Endogenous AIF protein levels were decreased in AIF-siRNA-treated cells, but not in ascorbate-treated cells (Fig. 4A). In parallel with AIF silencing, the populations of dead cells were decreased in the presence of ascorbate (Fig. 4B), implying that AIF is necessary for cell death induced by ascorbate in human breast cancer cells.

In this study, we demonstrate that ascorbate induces cell death in a caspase-independent manner through AIF release from mitochondria in human breast cancer cells. Biochemical analyses showed that ascorbate induces AIF release from mitochondria, thereby inducing cell death. However, MG132 as a blocker of AIF release and AIF-SiRNA failed to completely suppress cell death induced by ascorbate, suggesting that there may be another pathway by which ascorbate induces cell death, in addition to the AIF signal. Collectively, these findings suggest that AIF release from mitochondria is critical for inducing cell death in cells damaged by ascorbate.

\section{Acknowledgements}

This study was supported by KOSEF (Research Center for Women's Diseases) and Sookmyung Women's University (2006).

\section{References}

1. Padayatty SJ and Levine M: Reevaluation of ascorbate in cancer treatment: emerging evidence, open minds and serendipity. J Am Coll Nutr 19: 423-425, 2000.

2. Kao T, Meyers W and Post F: Inhibitory effects of ascorbic acid on growth of leukemic and lymphoma cell lines. Cancer Lett 70: 101-106, 1993.

3. Yanagisawa-Shiota F, Sakagami H, Kuribayashi N, Lida M and Sakagami T: Endonuclease activity and induction of DNA fragmentation in human myelogenous leukemic cell lines. Anticancer Res 15: 259-265, 1995.

4. Iwasaka K, Koyama N, Nogaki A, Maruyama S, Tamura A, Takano H, Takahama M, Kochi M, Satoh K and Sakagami H: Role of hydrogen peroxide in cytotoxicity induction by ascorbates and other redox compounds. Anticancer Res 18: 4333-4337, 1998.

5. Kang JS, Cho D, Kim YI, Hahm E, Kim YS, Jin SN, Kim HN, Kim D, Hur D, Park H, Hwang YI and Lee WJ: Sodium ascorbate (vitamin C) induces apoptosis in melanoma cells via the down-regulation of transferrin receptor dependent iron uptake. J Cell Physiol 204: 192-197, 2005.

6. Baader S, Bruchelt G, Carmine T, Lode H, Rieth A and Niethammer D: Ascorbic-acid-mediated iron release from cellular ferritin and its relation to the formation of DNA strand breaks in neuroblastoma cells. J Cancer Res Clin Oncol 120: 415-421, 1994.

7. Lee YS and Wurster RD: Potentiation of anti-proliferative effect of nitroprusside by ascorbate in human brain tumor cells. Cancer Lett 78: 19-23, 1994.

8. Maramag C, Menon M, Balaji KC, Reddy PG and Laxmanan S: Effect of vitamin $\mathrm{C}$ on prostate cancer cells in vitro: effect on cell number, viability, and DNA synthesis. Prostate 32: 188-195, 1997.

9. Menon M, Maramag C, Malhotra RK and Seethalakshmi L: Effect of vitamin $\mathrm{C}$ on androgen independent prostate cancer cells (PC3 and Mat-Ly-Lu) in vitro: involvement of reactive oxygen species-effect on cell number, viability and DNA synthesis. Cancer Biochem Biophys 16: 17-30, 1998.

10. Head KA: Ascorbic acid in the prevention and treatment of cancer. Altern Med Rev 3: 174-186, 1996.

11. Criollo A, Galluzzi L, Chiara Maiuri M, Tasdemir E, Lavandero S and Kroemer G: Mitochondrial control of cell death induced by hyperosmotic stress. Apoptosis 12: 3-18, 2007.

12. Wajant H: The Fas signaling pathway: more than a paradigm. Science 296: 1635-1636, 2002.

13. Green DR and Kroemer G: The pathophysiology of mitochondrial cell death. Science 305: 626-629, 2004

14. Zamzami N, Susin SA and Marchetti P: Mitochondrial control of nuclear apoptosis. J Exp Med 183: 1533-1544, 1996.

15. Sean PC, Valina LD and Ruth SS: Role of AIF in caspasedependent and caspase-independent cell death. Oncogene 23: 2785-2796, 2004.

16. Li LY, Luo $X$ and Wang $X$ : Endonuclease $G$ is an apoptotic DNase when released from mitochondria. Nature 412: 95-99, 2001.

17. Van Loo G, Schotte P, van Gurp M, Demol H, Hoorelbeke B, Gevaert K, Rodriguez I, Ruiz-Carrillo A, Vandekerckhove J, Declerc W, Beyaert R and Vandenabeele P: Endonuclease G: a mitochondrial protein released in apoptosis and involved in caspase-independent DNA degradation. Cell Death Differ 8: 1136-1142, 2001. 
18. Ashutosh S, Meenakshi T, Rohit AS, Ashok K, Anil KB, Virendra KB, Ramesh S, Kalyan M, Ashwani T and Madan MG: Molecular iodine induces caspase-independent apoptosis in human breast carcinoma cells involving the mitochondriamediated pathway. J Biol Chem 281: 19762-19771, 2006.

19. Yuste VJ, Moubarak RS, Delettre C, Bras M, Sancho P, Robert N, D'Alayer J and Susin SA: Cysteine protease inhibition prevents mitochondrial apoptosis-inducing factor (AIF) release. Cell Death Differ 12: 1445-1448, 2005.

20. Berridge MJ: Capacitative calcium entry. Biochem J 15: 1-11, 1995.

21. McConkey DJ and Orrenius S: The role of calcium in the regulation of apoptosis. Biochem Biophys Res Commun 239: 357-366, 1997.

22. Olsson ME, Andersson CS, Oredsson S, Berglund RH and Gustavsson KE: Antioxidant levels and inhibition of cancer cell proliferation in vitro by extracts from organically and conventionally cultivated strawberries. J Agric Food Chem 54: $1248-1255,2006$

23. Gonzalez MJ, Mora EM, Miranda-Massari JR, Matta J, Riordan HD and Riordan NH: Inhibition of human breast carcinoma cell proliferation by ascorbate and copper. PR Health Sci J 21: 21-23, 2002.

24. Kim KN, Pie JE, Park JH, Park YH, Kim HW and Kim MK: Retinoic acid and ascorbic acid act synergistically in inhibiting human breast cancer cell proliferation. J Nutr Biochem 17: 454-462, 2006.
25. Roomi MW, Lvanov V, Kalinovsky T, Niedzwiecki A and Rath $\mathrm{M}$ : In vitro and in vivo antitumorigenic activity of a mixture of lysine, proline, ascorbic acid, and green tea extract on human breast cancer lines MDA-MB-231 and MCF-7. Med Oncol 22: 129-138, 2005.

26. Knowles HJ, Raval RR, Harris AL and Ratcliffe PJ: Effect of ascorbate on the activity of hypoxia-inducible factor in cancer cells. Cancer Res 63: 1764-1768, 2003.

27. Domenicotti C, Marengo B, Verzola D, Garibotto G, Traverso N, Patriarca S, Maloberti G, Cottalasso D, Poli G, Passalacqua M, Melloni E, Pronzato MA and Marinari UM: Role of PKC-delta activity in glutathione-depleted neuroblastoma cells. Free Radic Biol Med 35: 504-516, 2003.

28. Lee YS: Role of intracellular $\mathrm{Ca}^{2+}$ signal in the ascorbate-induced apoptosis in a human hepatoma cell line. Arch Pharm Res 27: 1245-1252, 2004.

29. Makino Y, Sakagami H and Takeda M: Induction of cell death by ascorbic acid derivatives in human renal carcinoma and glioblastoma cell lines. Anticancer Res 19: 3125-3132, 1999.

30. Park S, Han SS, Park CH, Hahm ER, Lee SJ, Park HK, Lee SH, Kim WS, Jung CW, Park K, Riordan HD, Kimler BF, Kim K and Lee JH: L-Ascorbic acid induces apoptosis in acute myeloid leukemia cells via hydrogen peroxide-mediated mechanisms. Int J Biochem Cell Biol 36: 2180-2195, 2004.

31. Cande C, Vahsen N, Metivier D, Tourriere H, Chebli K, Garrido C, Tazi J and Kroemer G: Regulation of cytoplasmic stress granules by apoptosis-inducing factor. J Cell Sci 117: 4461-4468, 2004. 